\title{
Does propranolol alter the vascular response to phenylephrine before or during halothane anaesthesia in patients with coronary artery disease?
}

Preoperative beta-adrenergic blockade with propranolol, by allowing unopposed alpha-adrenergic stimulation in response to stress, has been suggested as a factor contributing to hypertension following coronary artery bypass surgery ( $C A B G$ ). Thus, one might expect to find an exaggerated haemodynamic response to phenylephrine (PHE), an alpha, agonist. To study this, the cardiovascular response to PHE infusion at 30,40, and 50 $\mu g \cdot \mathrm{min}^{-1}$ prior to and during halothane anaesthesia was measured before surgical stimulation during elective CABG in patients taking chronic propranolol therapy and compared with that of patients not taking any cardiovascular medications. Chronic propranolol therapy did not alter the haemodynamic response to PHE, before or during halothane anaesthesia, and the incidence of postoperative hypertension requiring vasodilator therapy was the same for both groups.

On a incriminé l'usage préopératoire de propranolol en tant que facteur associé à l'hypertension postopératoire après chirurgie cardiaque, puisque la stimulation alpha-adrénergique secon-

\section{Key words}

ANAESTHESIA: cardiac;

ANAESTHETICS, VOLATILE: halothane;

SYMPATHETIC NERVOUS SYSTEM: pharmacology, propranolol, phenylephrine.

From the Departments of Anesthesiology, University of Tennessee Medical School, Memphis, Tennessee,* and University of Alexandria School of Medicine, Alexandria. Egypt. $\dagger$

The study was done at the Cleveland Clinic, Department of Cardiothoracic Anesthesia, 9500 Euclid Avenue, Cleveland, Ohio 44106.

Address correspondence to: Dr. D. F. Grum.

Accepted for publication Ist August, 1991. daire au stress serait alors sans contrepartie bêta. On pourrait donc dans ce contexte supposer une réponse exagérée à la phényléphrine qui est un stimulant alpha. Nous avons éprouvé cette hypothèse en mesurant l'effet hémodynamique d'une perfusion de phényléphrine à raison de 30,40 et $50 \mu \mathrm{g} \cdot \mathrm{min}^{-1}$ avant et pendant une anesthésie à l'halothane (avant l'incision) chez des candidats à une revascularisation coronarienne qui prenaient soit du propranolol de façon chronique soir aucune médication de nature cardiovasculaire. La thérapie chronique au propranolol ne modifiait pas l'effet hémodynamique de la phényléphrine avec ou sans halothane et $n$ 'influençait en rien l'incidence d'hypertension postopératoire.

Acute systemic hypertension following coronary artery bypass graft surgery (CABG) is distinct from the increased blood pressure caused by pain, arousal from anaesthesia, hypothermia, myocardial ischaemia, and hypovolaemia. ${ }^{1-4}$ It is more frequent in patients with normal left ventrical function, ${ }^{3}$ but does not have a direct relationship to a history of hypertension or the preoperative use of antihypertensive drugs. Because of the association of hypertension with ischaemic heart disease, ${ }^{5}$ patients presenting for CABG are often receiving antihypertensive medication. Propranolol is a preferred agent, utilised alone or in combination with other drugs for hypertension, and for treatment of angina pectoris because of its beneficial effects on the transmural myocardial distribution of blood flow ${ }^{6}$ and on the determinants of myocardial oxygen consumption. ${ }^{7}$ However, preoperative propranolol therapy has been suggested as a factor that may increase the risk of hypertension following CABG, perhaps through unopposed alpha-adrenergic stimulation. ${ }^{8}$ Alpha-adrenergic stimulation that results in increased peripheral vascular resistance has been reported to occur during and after CABG by other investigators. ${ }^{9-11}$ 
Phenylephrine (PHE) is an alpha, agonist commonly used to support systemic blood pressure during anaesthesia for CABG. If, in patients receiving propranolol, unopposed alpha-adrenergic system secondary to beta-adrenergic blockade was a factor in the development of postoperative hypertension, an exaggerated haemodynamic response to PHE might be present before and during anaesthesia. To investigate this the cardiovascular response to PHE infusion was studied prior to and during anaesthesia before surgical stimulation in patients for elective CABG who were taking preoperative propranolol therapy alone. These results were compared with those of a previously reported control group of patients receiving no medications, who underwent the same dose regimen under identical experimental conditions. ${ }^{12}$

\section{Methods}

After approval of the protocol by the institutional Human Research Projects Committee and Institutional Review Board, and after obtaining written informed consent from all subjects, two groups of patients without systemic disease and with normal left ventricular function who were scheduled for elective CABG were studied. Group I $(n=9)$ comprised patients taking oral propranolol for chronic antianginal therapy (dose: $40-200 \mathrm{mg} \cdot \mathrm{day}^{-1}$ ). The antianginal response of each patient to propranolol was judged to be excellent by the patients and their cardiojogists. Propranolol was continued up to and including the morning of surgery. Group II $(n=8)$ consisted of patients who were not taking any chronic medications and served as a control. Although patients in either group rarely needed sublingual nitrates at rest to help control acute anginal attacks, all had severe coronary obstructive lesions in surgically critical locations demonstrated by cineangiography.

Premedication consisted of morphine sulfate (0.1 $\left.\mathrm{mg} \cdot \mathrm{kg}^{-1}, \mathrm{im}\right)$, scopolamine $(0.4 \mathrm{mg}, \mathrm{im})$, and transdermal nitroglycerin $(5-10 \mathrm{mg})$ administered one hour before arrival in the operating room suite. No patient had taken sublingual nitrates within the previous $12 \mathrm{hr}$. Oxygen, 3 $\mathrm{L} \cdot \mathrm{min}^{-1}$ by nasal prongs, was administered to all patients immediately upon arrival. The ECG was monitored for heart rate (HR), rhythm, and ST segment changes in the standard, augmented limb, and $\mathrm{V}_{5}$ leads. Catheters were placed in the radial artery for continuous recording of mean arterial blood pressure (MAP), in peripheral veins for fluid administration, and in the pulmonary artery for thermodilution cardiac output, central venous and pulmonary capillary wedge pressures (CVP, PCWP), and for continuous recording of mean pulmonary arterial pressures (PAM). Cardiac index (CI), systemic and pulmonary vascular resistances (SVR, PVR) were calculated.

Complete haemodynamic profiles were obtained in all
TABLE | Demographic data

\begin{tabular}{lll}
\hline & $\begin{array}{l}\text { Group I } \\
(n=9)\end{array}$ & $\begin{array}{l}\text { Group } / 1 \\
(n=8)\end{array}$ \\
\hline Age $(\mathrm{yr} \pm \mathrm{SD})$ & $55 \pm 10$ & $57 \pm 8$ \\
Sex $(\mathrm{M} / \mathrm{F})$ & $9 / 0$ & $8 / 0$ \\
Weight $(\mathrm{kg} \pm \mathrm{SD})$ & $81 \pm 21$ & $80 \pm 11$ \\
Pharm. therapy & & \\
$-\beta$-Blockers & 9 & 0 \\
- Nitrates within $24 \mathrm{hr}$ & 0 & 0 \\
- Other & 0 & 0 \\
Normal LV function & $9 / 9$ & $8 / 8$ \\
Vessels grafted & $2.4 \pm 0.7$ & $2.3 \pm 0.8$ \\
\hline
\end{tabular}

TABLE II Bascline haemodynamic data before and after halothane anaesthesia

\begin{tabular}{lccccc}
\hline & \multicolumn{2}{l}{ Before halothane } & & \multicolumn{2}{l}{ After halothane } \\
\cline { 2 - 3 } \cline { 5 - 6 } & Group I & Group II & & Group I & Group II \\
\hline HR & $58 \pm 3^{*}$ & $67 \pm 5$ & & $66 \pm 3 * \dagger$ & $73 \pm 3$ \\
MAP & $94 \pm 6$ & $94 \pm 6$ & & $80 \pm 6 \dagger$ & $74 \pm 4 \dagger$ \\
SVR & $1446 \pm 122$ & $1440 \pm 177$ & & $1372 \pm 70$ & $1400 \pm 176$ \\
PAM & $16 \pm 1$ & $18 \pm 2$ & & $16 \pm 1$ & $15 \pm 1$ \\
PVR & $72 \pm 40^{*}$ & $118 \pm 46$ & & $107 \pm 23 \dagger$ & $110 \pm 23$ \\
PCWP & $11 \pm 1$ & $10 \pm 1$ & & $10 \pm 1$ & $10 \pm 1$ \\
CVP & $8 \pm 1$ & $7 \pm 1$ & & $7 \pm 1$ & $7 \pm 1$ \\
Cl & $2.5 \pm 0.1$ & $2.8 \pm 0.3$ & $2.2 \pm 0.1 \dagger$ & $2.2 \pm 0.2 \dagger$ \\
\hline
\end{tabular}

Values are mean \pm SD. Group I: $n=9$. Group Il: $n=8$.

$\mathrm{HR}=$ Heart rate (beats $\left.\cdot \mathrm{min}^{-1}\right) ; \mathrm{MAP}=$ mean systemic anerial pressure $(\mathrm{mmHg}) ; \mathrm{SVR}=$ systemic vascular resistance $\left(\right.$ dyne $\cdot \sec ^{-1}$. $\left.\mathrm{cm}^{-5}\right): \mathrm{PAM}=$ pulmonary artery mean pressure $(\mathrm{mmHg}) ; \mathrm{PVR}=$ pulmonary vascular resistance (dyne $\cdot \mathrm{sec}^{-1} \cdot \mathrm{cm}^{-5}$ ); $\mathrm{PCWP}=$ pulmonary capillary wedge pressure $(\mathrm{mmHg})$; $\mathrm{CVP}=$ central venous pressure) $(\mathrm{mmHg}) ; \mathrm{Cl}=$ cardiac index (litres $\cdot \mathrm{min}^{-1} \cdot$ meter $\left.^{2}\right)$.

*Significant difference $(P<0.05)$ compared with value in Group II. $\dagger$ Significant difference $(P<0.05)$ compared with value before halothane.

patients while awake (trial one) before and during PHE infusions at 30,40 , and $50 \mu \mathrm{g} \cdot \mathrm{min}^{-1}$. These doses were commonly employed for support of the systemic blood pressure during CABG at our institution at the time of the study. The endpoint for each rate of PHE infusion, at which time measurements were made, was stabilisation of the response of the systemic blood pressure (approximately five minutes). Upon completion of these measurements, the haemodynamic effects of PHE were allowed to subside and to return to the pre-PHE baseline in all patients. Anaesthesia was then induced with thiopentone (2-3 $\left.\mathrm{mg} \cdot \mathrm{kg}^{-1}\right)$, and a pancuronium-metocurine mixture $\left(0.4 \mathrm{mg} \cdot \mathrm{ml}^{-1}+1.6 \mathrm{mg} \cdot \mathrm{ml}^{-1}: 1 \mathrm{ml} \cdot 10 \mathrm{~kg}^{-1}\right)$ was given for neuromuscular blockade. Anaesthetic maintenance was begun with halothane, $1 \%$ inspired, in oxygen. Lidocaine (100 mg) was used to attenuate the haemodynamic response to tracheal intubation. The ventilator was adjusted 
TABLE III Trial one: hacmodynamic response to phenylephrine before halothane anaesthesia

\begin{tabular}{|c|c|c|c|c|c|c|}
\hline & \multicolumn{3}{|c|}{$\begin{array}{l}\text { Group I } \\
\text { Phenylephrine dose (mcg/min) }\end{array}$} & \multicolumn{3}{|c|}{$\begin{array}{l}\text { Group II } \\
\text { Phenylephrine dose (mcg/min) }\end{array}$} \\
\hline & 30 & 40 & 50 & 30 & 40 & 50 \\
\hline$\Delta \mathrm{HR}$ & $-7 \pm 4$ & $-10 \pm 5$ & $-12 \pm 8$ & $-7 \pm 4$ & $-10 \pm 5$ & $-13 \pm 6$ \\
\hline$\triangle M A P$ & $10 \pm 3$ & $15 \pm 4$ & $21 \pm 5$ & $5 \pm 6$ & $10 \pm 8$ & $15 \pm 9$ \\
\hline$\Delta S V R$ & $349 \pm 176$ & $461 \pm 206$ & $681 \pm 261$ & $116 \pm 229 \dagger$ & $255 \pm 311$ & $413 \pm 416$ \\
\hline$\triangle P A M$ & $2 \pm 4$ & $5 \pm 4$ & $7 \pm 5$ & $3 \pm 2$ & $4 \pm 4$ & $5 \pm 3$ \\
\hline$\triangle P V R$ & $25 \pm 77$ & $44 \pm 84$ & $56 \pm 87$ & $10 \pm 52$ & $44 \pm 51$ & $45 \pm 45$ \\
\hline$\triangle P C W P$ & $2 \pm 2$ & $4 \pm 2$ & $6 \pm 3^{*}$ & $2 \pm 1$ & $3 \pm 1$ & $3 \pm 2^{*}$ \\
\hline$\Delta \mathrm{CVP}$ & $2 \pm 2$ & $3 \pm 3$ & $4 \pm 4$ & $2 \pm 2$ & $2 \pm 3$ & $3 \pm 5$ \\
\hline$\Delta \mathrm{Cl}$ & $-0.3 \pm 0.3$ & $-0.4 \pm 0.2$ & $-0.5 \pm 0.2$ & $-0.2 \pm 0.3$ & $-0.3 \pm 0.4$ & $-0.4 \pm 0.4$ \\
\hline
\end{tabular}

Values are mean \pm SD changes $(\Delta)$ from bascline. Group I: $n=9$. Group II: $n=8$. Refer to Table I for abbreviations. All changes in each group are significant $(P<0.05)$ when compared with respective unanaesthetized baseline, except when noted $(\dagger)$. Significant change $(P<0.05)$ compared response to same dose of PHE in the other group $\left({ }^{*}\right)$. No significant differences $(P<0.05)$ between groups by ANOVA for changes in any haemodynamic variable in response to PHE.

to maintain normal acid-base status and $\mathrm{PaCO}_{2}$ in each patient. After cardiovascular stability was achieved in the absence of any surgical stimulation during halothane administration (approximately $20-30 \mathrm{~min}$ ), new baseline haemodynamic measurements were obtained and the cardiovascular response to PHE infusions at 30,40 and 50 $\mu \mathrm{g} \cdot \mathrm{min}^{-1}$ were measured again (trial two). Anaesthesia was maintained with halothane during and following cardiopulmonary bypass (CPB).

Data were compared using paired $t$ tests, the Bonferroni inequality adjustment and analysis of variance (ANOVA) to detect significant $(P<0.05)$ differences within and between the two groups before and during anaesthesia. The position and slope of the response curves for each cardiovascular variable were compared. In addition, since the number of patients in each group was small, power analysis (alpha $=0.05$, two-tailed; beta $=0.20$ ) was done to assess the likelihood of Type II error.

\section{Results}

Both groups were similar (Table I) with regard to the demographic variables of age, weight, sex, ASA class, left ventricular function and the surgery performed (number of vein grafts and whether an internal mammary artery was used). Blood pressures and heart rates upon arrival in the operating room suite did not differ from those recorded in the hospital rooms. No arrhythmias or signs and symptoms of ischaemia (angina pectoris or other symptoms while awake, ST-T segment changes, sudden large increase in PCWP) were observed in any patient at any time during the study. No patients required any pharmacological intervention during the study. Arterial blood gas analyses before and during halothane anaesthesia were normal.

Baseline haemodynamic variables of both groups before halothane anaesthesia are shown in Table II (left columns). These values were comparable, except for $\mathrm{HR}$ which was lower in Group I patients $(P<0.05)$. Haemodynamic variables (Table III, Trial One) during PHE administration at all three infusion rates prior to anaesthesia were different from baseline $(P<0.05)$. PHE caused increases in MAP and SVR (except at PHE: $30 \mu \mathrm{g} \cdot \mathrm{min}^{-1}$ in Group II), accompanied by reductions in $\mathrm{HR}$ and $\mathrm{CI}$. Comparison of the overall cardiovascular response curves of the two groups to PHE showed no differences: chronic propranolol therapy did not affect the response to PHE in unanaesthetized patients. The reliability of this conclusion was substantiated by power analysis.

Following stabilisation during halothane anaesthesia, the MAP was lower than baseline values prior to anaesthesia in both groups (Table II). The decreases were statistically similar and were accompanied by a reduction in $\mathrm{Cl}$ in each group. Following infusion of PHE (Table IV, Trial Two), the MAP, SVR, PCWP and CVP (except at PHE: 30 $\mu \mathrm{g} \cdot \mathrm{min}^{-1}$ in Group I) increased from baseline values under anaesthesia in both groups, with corresponding decreases in HR $(P<0.05)$. The effect on $\mathrm{Cl}$ was insignificant at all levels of PHE infusion during halothane anaesthesia in both groups. Comparison of the overall cardiovascular response curves of the two groups to PHE during halothane showed no significant difference: chronic propranolol therapy did not affect the response to PHE in anaesthetized patients. Power analysis suggests that this conclusion would not be altered by studying additional patients.

Similarly, there was no difference in the response to PHE prior to anaesthesia compared with that obtained during halothane administration in patients taking propranolol. Halothane did not affect the overall haemodynamic response to PHE in patients taking chronic propranolol therapy.

The incidence of haemodynamic instability was low and similar for both groups prior to CPB. All patients except 
TABLE IV Trial two: haemodynamic response to phenylephrine during halothane anaesthesia

\begin{tabular}{|c|c|c|c|c|c|c|}
\hline & \multicolumn{3}{|c|}{$\begin{array}{l}\text { Group I } \\
\text { Phenylephrine dose ( } \mathrm{mcg} / \mathrm{min})\end{array}$} & \multicolumn{3}{|c|}{$\begin{array}{l}\text { Group II } \\
\text { Phenylephrine dose ( } \mathrm{mcg} / \mathrm{min})\end{array}$} \\
\hline & 30 & 40 & 50 & 30 & 40 & 50 \\
\hline$\Delta H R$ & $-7 \pm 7$ & $-12 \pm 8$ & $-16 \pm 5$ & $-10 \pm 7$ & $-15 \pm 9$ & $-18 \pm 10$ \\
\hline$\triangle M A P$ & $8 \pm 4$ & $15 \pm 7$ & $26 \pm 8$ & $10 \pm 11$ & $16 \pm 10^{*}$ & $19 \pm 13$ \\
\hline$\Delta S V R$ & $289 \pm 279$ & $564 \pm 341$ & $932 \pm 291$ & $444 \pm 163^{*}$ & $522 \pm 325$ & $526 \pm 325$ \\
\hline$\triangle P A M$ & $1 \pm 2$ & $4 \pm 1$ & $6 \pm 2$ & $1 \pm 2^{*}$ & $3 \pm 3$ & $5 \pm 5$ \\
\hline$\Delta P V R$ & $-8 \pm 50 \dagger$ & $24 \pm 39 t$ & $47 \pm 46 \dagger$ & $-2 \pm 37 \dagger$ & $10 \pm 46+$ & $35 \pm 43 \dagger$ \\
\hline$\triangle P C W P$ & $2 \pm 1$ & $3 \pm 2$ & $5 \pm 3$ & $2 \pm 2$ & $4 \pm 2$ & $4 \pm 3$ \\
\hline$\Delta C V P$ & $1 \pm 1$ & $2 \pm 2$ & $3 \pm 2$ & $3 \pm 3$ & $3 \pm 3$ & $4 \pm 2$ \\
\hline$\Delta \mathrm{Cl}$ & $-0.1 \pm 0.6 t$ & $-0.3 \pm 0.4 \dagger$ & $-0.4 \pm 0.3 \dagger$ & $-0.4 \pm 0.3 \dagger$ & $-0.5 \pm 0.4 \dagger$ & $-0.5 \pm 0.5 t$ \\
\hline
\end{tabular}

Values are mean \pm SD changes $(\Delta)$ from anaesthetized baseline. Group: $1 n=9$. Group 2: $n=8$. Refer to Table I for abbreviations. All changes significant $(P<0.05)$ compared to respective anaesthetized baseline except $(\dagger)$. No significant change $(P<0.5)$ compared to response to comparable PHE dose before halothane except $\left(^{*}\right)$. No significant differences $(P<0.05)$ between groups by ANOVA for changes in any haemodynamic variable in response to PHE.

two in each group received an infusion of either sodium nitroprusside or nitroglycerin following cardiopulmonary bypass (CPB) to control systemic hypertension (maintain systolic $\mathrm{BP} \leq 140$ or MAP $\leq 95 \mathrm{mmHg}$ respectively). No patient had hypertension immediately upon admission to the postoperative recovery suite. Five patients in each group required an infusion of small doses of sodium nitroprusside or nitroglycerin at some time during the first $24 \mathrm{hr}$ after surgery to control hypertension (SBP $>140$, or MAP $>95 \mathrm{mmHg}$ respectively). The duration of this therapy was short ( $\leq 12 \mathrm{hr}$ ) in each patient.

\section{Discussion}

The effects of chronic propranolol therapy on the cardiovascular response to alpha-adrenergic stimulation have not been previously described. Phenylephrine is an alphaagonist drug which preferentially stimulates the alpha, adrenoceptor ${ }^{13}$ and is commonly utilized to support blood pressure at various times during CABG surgery. Propranolol, by virtue of its inhibition of beta-adrenergic mediated arteriolar vasodilatation and the possible resultant unopposed alpha-adrenergic predominance, might be expected to modify the response to PHE. " One important finding in this study is the demonstration that this does not occur at PHE dosages commonly administered during CABG. A normal pressor response to PHE can be expected under these conditions. The other important result is that halothane anaesthesia does not influence the overall alpha ${ }_{1}$ adrenoceptor-mediated pressor response in patients taking propranolol alone.

Hypertension is one of the most frequent, occurring in $33 \%$ to $76 \%$ of patients, ${ }^{2,5,14}$ and potentially dangerous ${ }^{4,15}$ complications following CABG. However, little effort has been directed toward investigating drug interaction in its aetiology. Our investigation is unique in that patients in the study group were taking only propranolol and no other medication, while the clinical controls were not taking any medications chronically that could have influenced results. This afforded us the opportunity to investigate the potential interaction of PHE with propranolol alone. Although the degree of preoperative beta-adrenergic blockade using an infusion of a beta-adrenergic agonist was not evaluated and compared in the two groups, patients in Group I had a lower heart rate than those in Group II, suggesting that some degree of beta-adrenergic blockade was present.

Preoperative medication was administered to help allay anxiety and to minimize any resulting increase in sympathetic tone. It was identical in each patient and was considered to be a necessary part of each patient's preparation for the stress of surgery and anaesthesia. ${ }^{16}$ Interaction of nitroglycerin (NTG) from a transdermal patch was unlikely, since the expected low $\left(0.2-0.3 \mathrm{ng} \cdot \mathrm{ml}^{-1}\right)$ plasma concentration at one and two hours ${ }^{17}$ are below those required (1-2 $\mathrm{ng} \cdot \mathrm{ml}^{-1}$ ) for venodilatation or arterial dilatation. ${ }^{18}$ Acid-base abnormalities can influence alpha ${ }_{1}$ adrenoceptor responses. ${ }^{19}$ Acid-base status was normal in all subjects during the protocol while unanaesthetized, and ventilation was adjusted to maintain normocapnia during halothane anaesthesia. Pharmacological therapy for correction of a metabolic abnormality was not required.

Preoperative comparison of the haemodynamic values for the two groups revealed a lower heart rate in the propranolol group. The groups showed no differences in any other cardiovascular variable, arterial blood gas, or arterial $\mathrm{pH}$ values. This is similar to the preoperative data of Kopriva et al., ${ }^{20}$ who also studied ten CABG patients taking oral propranolol up to five to six hours before induction of anaesthesia and who, with the exclusion of nitroglycerin, received similar medication.

Release of norepinephrine from sympathetic neurons is potentiated by presynaptic beta-adrenergic receptors. The role of diminished release of norepinephrine in the anti- 
hypertensive effect of propranolol is not known. Although short-term administration causes an increase in peripheral vascular resistance resulting from blockade of vascular beta ${ }_{2}$ receptors and compensatory sympathetic reflexes that activate vascular alpha-adrenergic receptors, ${ }^{21}$ longterm administration causes a decrease in vascular resistance in hypertensive patients. ${ }^{22}$ Whelton et al. ${ }^{11}$ found an increase in the incidence of postoperative hypertension in CABG patients who were taking chronic propranolol therapy. They proposed that the increased level of circulating catecholamines that they found following CPB in all patients in response to the effects of cardiac surgery produced unopposed alpha-adrenergic stimulation in patients taking propranolol, with resulting vasoconstriction and hypertension. Similarly produced hypertension has been described during propranolol therapy of hyperadrenergic states ${ }^{23.24}$ and following catecholamine administration to both normotensive ${ }^{25}$ and hypertensive ${ }^{26}$ patients taking chronic propranolol. Phenylephrine administration produced increases in blood pressure and increased vascular resistance in all patients in our study. However, the overall haemodynamic response to PHE in patients taking propranolol did not differ from that found in controls either before or during halothane anaesthesia. Chronic propranolol did not produce a clinically measurable, unbalanced adrenergic baseline state in our patients while awake or anaesthetised, nor an unopposed alphaadrenergic responsiveness during PHE administration. This result is consistent with the findings of Sill et al. ${ }^{27}$ who found no relationship between the haemodynamic state and log propranolol plasma concentration in the surgically unstimulated patient during light halothane anaesthesia. Similarly, Kopriva et al. ${ }^{19}$ found that continued oral administration of propranolol before surgery did not alter the haemodynamic response to tracheal intubation or to the events of surgery before CPB in patients anaesthetized with halothane, $0.5-2 \%$ in nitrous oxide-oxygen, $60-40 \%$, and pancuronium. The haemodynamic response to catecholamine administration following CPB in patients taking chronic propranolol has not been studied.

Halothane increases venous compliance ${ }^{28}$ and, in patients with high sympathetic tone, decreases systemic vascular resistance. ${ }^{29}$ Various central and peripheral actions play a role in halothane-mediated vascular smooth muscle relaxation, ${ }^{30}$ including the inhibition of vasoconstrictor actions of catecholamines, both in vivo ${ }^{31}$ and in vitro. ${ }^{32,33}$ These mechanisms undoubtedly were responsible for the decrease in MAP observed in both groups during halothane anaesthesia. However, we found that administration of halothane anaesthesia to patients taking chronic propranolol therapy did not modify the overall cardiovascular response to PHE: the magnitude and direction of haemodynamic changes were the same in patients before and during anaesthesia. This conflicts with the recent report by Kenny et al. ${ }^{34}$ that the alpha ${ }_{1}$ pressor response is attenuated in chronically instrumented dogs. They demonstrated that the responses of SBP and DBP to PHE were shifted to the right by halothane anaesthesia. However, they studied animals subjected to ganglionic and cholinergic, as well as beta adrenergic blockade, in doses appropriate to block reflex change in heart rate. Because we attempted to measure vascular responsiveness to PHE in the presence of propranolol alone, we did not undertake any of the above measures. The dissimilar results in our study, therefore, may be due to differences in methodology as well as to species variation.

In conclusion, we found that, in patients with coronary artery disease and normal left ventricular function, the overall haemodynamic response to phenylephrine given in doses commonly administered during CABG surgery is not altered by chronic propranolol therapy either before or during anaesthesia with halothane, $1 \%$ inspired, in oxygen. Propranolol has been demonstrated to increase the risk of unopposed alpha-adrenergic stimulation under certain clinical conditions, and has been suggested to play a role in the occurrence of hypertension following CABG. However, we did not find an increased clinical responsiveness to alpha, adrenergic stimulation in patients with coronary artery disease before the onset of surgical stimulation in a select group of patients taking propranolol alone. This may not necessarily be the case in the majority of patients who are taking other cardiovascular drugs in addition to beta-adrenergic blockers, or following cardiopulmonary bypass. Although the requirement for treatment of postoperative hypertension was similar in both groups, the study was not designed to reevaluate any correlation between preoperative propranolol therapy and the incidence of postoperative hypertension. Further investigation into the cause of this clinical entity is required.

\section{Acknowledgement}

The authors wish to thank Kavita Badhwar, M.A., Department of Biostatistics and Epidemiology, the Cleveland Clinic, for her assistance in the statistical analysis of the data.

\section{References}

1 Estafanous FG, Tarazi RC, Viljoen JF, El Tawil MY. Hypertension following myocardial revascularization. Am Hear J 1973; 85: 732-8.

2 Viljoen JF, Estafanous FG, Tarazi RC. Acute hypertension immediately following coronary artery surgery. $J$ Thor Cardiovasc Surg 1976; 71: 548-50. 
3 Fouad FM, Estafanous FG, Tarazi RC. Hemodynamics of postmyocardial revascularization hypertension. Am J Cardiol 1978; 41: 564-9.

4 Estafanous $F G$, Tarazi $R C$. Systemic arterial hypertension associated with cardiac surgery. Am J Cardiol 1980; 46: 685-94.

5 Kannel WB, Gordon T, Castelli WP. Margolis JR. Electrocardiographic evidence of left ventricular hypertrophy and risk of coronary heart disease: the Framingham study. Ann Intern Med 1970; 72: 813-22.

6 Stein PD, Brooks HL, Marson JL, Hyland JW. Effects of beta-adrenergic blockade on coronary blood flow. Cardiovasc Res 1968; 2: 62-7.

7 Armstrong $P W$, Chiong MA, Parker JO. Effects of propranolol on the hemodynamic, coronary sinus blood flow and myocardial metabolic response to atrial pacing. Am J Cardiol 1977; 40: 83-9.

8 Whelton PK, Flaherty JT, MacAllister NP et al. Hypertension following coronary artery bypass surgery. Hypertension 1980; 2: 291-8.

9 Roberts AJ, Subramanian VA, Herman SD et al. Systemic hypertension associated with coronary artery bypass surgery. J Thor Cardiovasc Surg 1977; 74: 846-59.

10 Pratilas V, Vlachakis ND, Litwak R. Hypertension and plasma catecholamines following aorto-coronary by-pass surgery. Clin Res 1977; 25: 244A.

II Replogle R, Levy M, DeWall RA, Lillehei RC. Catecholamine and serotonin response to cardiopulmonary bypass. J Thor Cardiovasc Surg 1962; 44: 638-48.

12 Grum DF, Azmy SS. Halothane anaesthesia does not modify the cardiovascular response to phenylcphrine in man. Can J Anaesth 1990; 37: 873-7.

13 van Meel JCA. J Pharmacol Exp Ther 1981; 219: 760-7.

14 Hoar PF, Hickey RF, Ullyot DJ. Systemic arterial hypertension following myocardial revascularization. J Thor Cardiovasc Surg 1976; 71: 859-64.

15 Haggendal E, Johansson B. Physiological aspects of the blood brain barrier change in acute arterial hypertension. Eur Neurol 1972; 6: 24-8.

16 Waller JL, Zaidan JR, Kaplan JA, Bauman DI. Hemodynamic responses to preoperative vascular cannulation in patients with coronary artery discase. Anesthesiology 1982; 56: 219-21.

17 Corwin S, Reiffel JA. Nitrate therapy for angina pectoris. Current concepts about mechanism of action and evaluation of currently available preparations. Arch Intern Med 1985; 145: 538-43.

18 Armstrong PW, Armstrong JA, Marks GS. Pharmacokinetic-hemodynamic studies of intravenous nitroglycerin in congestive heart failure. Circulation 1980; 62: 160-6.

19 McGrath JC. The variety of vascular alpha-adrenoceptors. Trends Pharmacol Sci 1983; 4: 14-8.
20 Kopriva CJ, Brown ACD, Pappas G. Hemodynamics during general anesthesia in patients receiving propranolol. Anesthesiology 1978; 48: 28-33.

21 Nies $A S$, Evans $G H$, Shand $D G$. Regional hemodynamic effects of beta-adrenergic blockade with propanolol in the unanesthetized primate. Am Heart J 1973; 85: 97-102.

22 Man in't Veld AJ, Van den Meiracker AH, Schalekamp $M A$. Do beta-blockers really increase peripheral vascular resistance? Review of the literature and new observations under basal conditions. Am J Hypertens 1988; 1: 91-6.

23 Pritchard $B N C$, Ross EJ. Use of propranolol in conjunction with alpha receptor blocking drugs in pheochromocytoma. Am J Cardiol 1966; 18: 394-8.

24 Blum I, Atsmon A, Steiner $M$, Wysenbeek $H$. Paradoxical rise in blood pressure during propranolol treatment. BMJ 1975; $4: 623$.

25 Harris WS, Schoenfeld CD, Brooks RH, Weissler AM. Effect of beta-adrenergic blockade on the hemodynamic responses to epinephrine in man. Am J Cardiol 1966; 17 : 484-92.

26 Vlachakis ND, DeGuia $D$, Mendlowitz $M$. Blood pressure responses to catecholamines during beta-adrenergic blockade with propranolol in hypertensive subjects. Chest 1977; 71: 38-43.

27 Sill JC, Nugent M, Moyer TP, Torres LE, Schaff $H V$. Tinker $J H$. Influence of propranolol plasma lcvels on hemodynamics during coronary artery bypass surgery. Anesthesiology 1984; 60: 45-63.

28 Caffrey JA, Eckstein JW, Hamilton, Abboud FM. Forearm venous and arterial responses to halothane and cyclopropane. Anesthesiology 1965; 26: 786-90.

29 Reiz $S$, Balfours $E$, Gustavsson B et al. Effects of halothane on coronary hemodynamics and myocardial metabolism in patients with ischaemic heart disease and heart failure. Acta Anaesthesiol Scand 1982; 26: 133-8.

30 Larach DR, Schuler HG, Derr JA, Larach MG, Hensley $F A$, Zelis $R$. Halothane selectively attenuates alpha $a_{2}$-adrenoceptor mediated vasoconstriction, in vivo and in vitro. Anesthesiology 1987; 66: 781-91.

31 Christophoro MF, Brody MJ. The effects of halothane and cyclopropane on skeletal muscle vessels and baroreceptor reflexes. Anesthesiology 1968; 29: 36-43.

32 Price $M L$, Price $H L$. Effects of general anesthetics on contractile responses of rabbit aortic strips. Anesthesiology $1962 ; 23$ : 16-20.

33 Clark SC, MacCannell $K L$. Vascular responses to anesthetic agents. Can Anaesth Soc J 1975; 22: 20-33.

34 Kenny D, Pelc LR, Brooks HL, Kampine JP. Schmeling $W T$, Warltier DC. Alterations of alpha ${ }_{1}$ and alpha $_{2}$ adrenoceptor-mediated pressor responses by halothane and isoflurane anesthesia. Anesthesiology 1989; 71: 224-34. 